\title{
DIMENSI KEPATUHAN WAJIB PAJAK ORANG PRIBADI PADA KPP PRATAMA SUKOHARJO
}

\author{
Esti Kurnia Sandy (2016030087) \\ E-mail : estikurnia464@gmail.com \\ Fakultas Ekonomi dan Bisnis, Jurusan Akuntansi \\ Universitas Islam Batik Surakarta
}

\begin{abstract}
Taxes are a source of state revenue that is used to build and improve infrastructure while enhancing the country's economy. In this study aims to examine the effect of service quality, religiosity of tax payments, tax amnesty policies, tax penalties, and the modern tax administration system on the compliance of individual taxpayers at KPP Pratama Sukoharjo. The population in this study is all private taxpayers who are registered in KPP Pratama Sukoharjo. The number of samples used in this research are 100 taxpayers registered in KPP Pratama Sukoharjo with Accidental Sampling techniques. Data collection using a questionnaire or questionnaire. The analysis method used by using multiple linear regression analysis. The results showed there was a positive influence between tax sanctions and the modern tax administration system on tax compliance for taxpayers at Sukoharjo KPP. Whereas service quality, religiosity of tax payments, and tax amnesty policies have a negative effect on taxpayers' compliance with Sukoharjo KPP. The benefit of this research is to improve information on taxation aspects, especially the increase in taxpayers in complying with taxation rules.
\end{abstract}

Keywords: Service, Religiosity, Tax Amnesty, Sanctions, Modern Administration System, WPOP Compliance

\begin{abstract}
Abstrak
Pajak merupakan sumber penerimaan negara yang digunakan untuk membangun serta memperbaiki infrastruktur maupun meningkatkan perekonomian negara. Dalam penelitian ini bertujuan untuk menguji pengaruh kualitas layanan, religiuitas pembayaran pajak, kebijakan tax amnesty, sanksi perpajakan, dan sistem administrasi perpajakan modern terhadap kepatuhan wajib pajak orang pribadi pada KPP Pratama Sukoharjo. Populasi dalam penelitian ini yaitu seluruh wajib pajak orang pribadi yang terdaftar di KPP Pratama Sukoharjo. Jumlah sampel yang digunakan dalam penelitan ini adalah 100 orang wajib pajak yang terdaftar di KPP Pratama Sukoharjo dengan tekhnik Accidental Sampling. Pengumpulan data menggunakan angket atau kuesioner. Metode analisis yang digunakan dengan menggunakan analisis regresi linier berganda. Hasil penelitian menunjukkan terdapat pengaruh positif antara sanksi perpajakan dan sistem administrasi perpajakan modern pada kepatuhan wajib pajak pada KPP Pratama Sukoharjo. Sedangkan kualitas layanan, religiuitas pembayaran pajak, dan kebijakan tax amnesty berpengaruh negatif pada kepatuhan wajib pajak pada KPP Pratama Sukoharjo. Manfaat penelitian ini yaitu untuk meningkatkan informasi pada aspek perpajakan, utamanya peningkatan wajib pajak dalam mematuhi aturan perpajakan.
\end{abstract}

Kata Kunci : Layanan, Religiuitas, Tax Amnesty, Sanksi, Sistem Administrasi Modern, Kepatuhan WPOP

\section{PENDAHULUAN}

Pajak merupakan sumber penerimaan negara yang digunakan untuk membangun dan memperbaiki infrastruktur maupun meningkatkan perekonomian negara. Setiap tahun pemerintahan selalu berupaya memaksimalkan penerimaan pajak. Peningkatan penerimaan negara dari sektor pajak sebagai salah satu sumber pembiayaan yang masih memungkinkan dan terbuka luas, didasarkan pada jumlah pembayar pajak dari tahun ke tahun yang diharapkan semakin banyak seiring bertambahnya jumlah penduduk dan kesejahteraaan masyarakat.

Faktor yang memengaruhi penerimaan pajak suatu negara diantaranya adalah tingkat kepatuhan Wajib Pajak di negara tersebut, (Chau, 2009). Kepatuhan Wajib Pajak (tax compliance) dapat dilihat dari sikap Wajib Pajak dalam mendaftarkan diri, menghitung pajaknya, menyetor maupun melaporkan Surat Pemberitahuan (SPT), 
kepatuhan dalam penghitungan dan pembayaran pajak, dan

kepatuhan dalam pembayaran tunggakan. Kepatuhan Wajib Pajak untuk memenuhi kewajiban perpajakannya perlu ditingkatkan demi terciptanya target pajak yang diinginkan.

Tujuan dari penelitian ini yaitu (1) Mengetahui pengaruh kualitas layanan terhadap kepatuhan wajib pajak orang pribadi pada KPP Pratama Sukoharjo. (2) Mengetahui pengaruh religiuitas pembayaran pajak terhadap kepatuhan wajib pajak orang pribadi pada KPP Pratama Sukoharjo. (3) Mengetahui pengaruh kebijakan tax amnesty terhadap kepatuhan wajib pajak orang pribadi pada KPP Pratama Sukoharjo. (4) Mengetahui pengaruh sanksi perpajakan terhadap kepatuhan wajib pajak orang pribadi pada KPP Pratama Sukoharjo. (5)Mengetahui pengaruh sistem administrasi perpajakan modern terhadap kepatuhan wajib pajak orang pribadi pada KPP Pratama Sukoharjo.

Manfaat dari penelitian ini (1) Manfaat Teoretis Hasil penelitian ini diharapkan dapat menambah pengetahuan yang berkaitan dengan pengaruh kualitas layanan, religiuitas pembayaran pajak, kebijakan tax amnesty, sanksi perpajakan, dan sistem administrasi perpajakn modern terhadap kepatuhan wajib pajak orang pribadi. (2) Manfaat Praktisi Hasil penelitian ini diharapkan dapat digunakan untuk meningkatkan informasi pada aspek perpajakan, utamanya peningkatan wajib pajak dalam mematuhi aturan perpajakan yakni pembayaran pajak ialah hal wajib yang harus dilaksanakan untuk membangun negara.

\section{TINJAUAN PUSTAKA}

\section{Teori Kepatuhan/Compliance theory}

Teori kepatuhan/compliance theory adalah teori yang menerangkan suatu kondisi dimana seseorang taat terhadap perintah/aturan yang diberikan. Kepatuhan perpajakan merupakan tanggung jawab kepada Tuhan, pemerintah dan rakyat sebagai wajib pajak/memenuhi semua kegiatan kewajiban perpajakan dan melaksanakan hak perpajakannya.

\section{Kualitas Layanan}

Pelayanan yang berkualitas ialah pelayanan yang memberikan kepuasan terhadap wajib pajak dan tetap memenuhi standar pelayanan. Kualitas Pelayanan merupakan tolak ukur seberapa bagus tingkat layanan yang diberikan mampu menyesuaikan pelanggan. Jadi kualitas pelayanan diwujudkan untuk memenuhi kebutuhan dan keinginan pelanggan serta ketetapan penyampaian pelayanan tersebut membagi harapan pelanggan.

\section{Religiuitas Pembayaran Pajak}

Religiusitas ialah seseorang yang menjalankan perintah agama dan menjauhi larangan agama. Seseorang yang dimaksud disini adalah wajib pajak. Wajib pajak yang lebih dekat dengan agama, maka wajib pajak tersebut akan berusaha menjalankan perintah agama. Wajib pajak menganggap jika melanggar peraturan agama maka wajib pajak akan merasa berdosa. Wajib pajak disini takut untuk melakukan hal yang tidak etis yaitu takutuntuk tidak mematuhi peraturan perpajakan.

\section{Kebijakan Tax Amnesty}

Pada Inside Tax Magazine - 37 (2016) membahas mengenai kebijakan tax amnesty yang merupakan awal dari reformasi perpajakan di Indonesia. Secara umum tax amnesty ialah pengampunan pajak yang diberikan oleh pemerintah bagi individu atau badan yang terindikasi melakukan penghindaran pajak dengan cara menyimpan uangnya di luar negeri dengan cara mengungkapkan harta dan membayar uang tebusan dengan tarif yang rendah sehingga mereka mau menarik uangnya untuk dibawa kembali ke Indonesia dan sekaligus untuk memudahkan pemerintah dalam hal ini Direktorat Jenderal Pajak untuk mendata kembali wajib pajak yang ada.

\section{Sanksi Perpajakan}

Sanksi perpajakan berfungsi sebagai dasar bagi pemerintah untuk menentukan wajib pajak yang melanggar peraturan. Artinya, jika kewajiban perpajakan tidak dilaksanakan, maka akan ada konsekuensi hukum yang bisa terjadi.

"Sanksi perpajakan merupakan jaminan bahwa ketentuan peraturan perundang-undangan perpajakan (norma perpajakan) akan dituruti/ditaati/dipatuhi. Atau bisa Wajib Pajak tidak melanggar norma perpajakan" (Mardiasmo, 2013). Sanksi pajak merupakan suatu alat pencegah bagi wajib pajak agar tidak melanggar ketentuan perpajakan.

\section{Sistem Administrasi Perpajakan Modern}

Sistem administrasi perpajakan modern merupakan penyempurnaan atau perbaikan kinerjanya. Pemerintah perlu merancang sistem pajak yang optimal dengan memperhatikan semua instrument yang dapat membantu kekuatan hukum pajak salah satunya dengan modernisasi adminsitrasi perpajakan. Modernisasi administrasi perpajakan merupakan penerapan sistem administrasi perpajakan yang transparan dan akuntabel, dengan memanfaatkan sistem teknologi informasi yang handal dan terkini sehingga dapat meningkatkan kepatuhan Wajib Pajak.

\section{Kepatuhan Wajib Pajak}

Kepatuhan wajib pajak merupakan kesadaran wajib pajak dalam memenuhi kewajiban pajaknya. "Kepatuhan memenuhi kewajiban 
perpajakan secara sukarela adalah tulang punggung sistem self assestment system, dimana wajib pajak bertanggungjawab menetapkan sendiri kewajiban

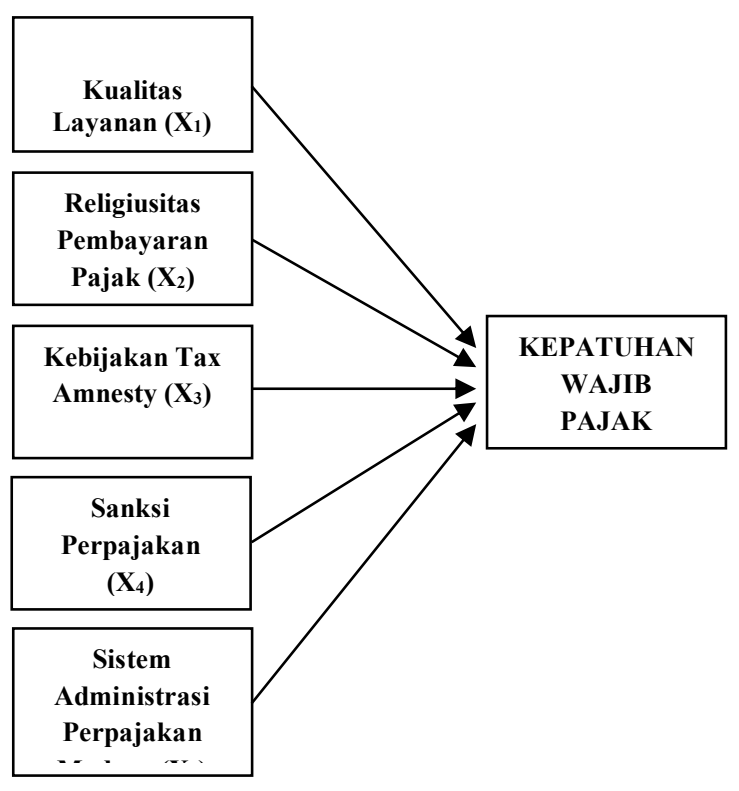

\section{HIPOTESIS}

1. Pengaruh kualitas layanan terhadap Kepatuhan Wajib Pajak Orang Pribadi Kualitas layanan adalah penyebab eksternal karena berasal dari luar Wajib Pajak atau hasil dari pemaksaan situasi. Persepsi Wajib Pajak mengenai kualitas layanan dari otoritas pajak akan mempengaruhi penilaian setiap Wajib Pajak untuk berperilaku sesuai dengan kewajiban perpajakan.

H1 : Kualitas layanan berpengaruh positif terhadap kepatuhan wajib pajak orang pribadi pada KPP Pratama Sukoharjo

2. Pengaruh religiuitas pembayaran pajak terhadap kepatuhan wajib pajak orang pribadi. Religiusitas merupakan faktor yang sangat mempengaruhi perilaku pembayar pajak dalam membayar pajak. Hasil serupa juga diungkapkan oleh Anggraeni (2017) religiusitas wajib pajak memiliki pengaruh positif terhadap kepatuhan pajak.

H2 : Religiuitas pembayaran pajak berpengaruh positif terhadap kepatuhan wajib pajak orang pribadi pada KPP Pratama Sukoharjo

3. Pengaruh tax amnesty terhadap kepatuhan wajib pajak orang pribadi yang meneliti tentang pengaruh sunset policy dan tax amnesty terhadap kepatuhan wajib pajak perpajakan dankemudian secara akurat dan tepat waktu membayar dan melaporkan pajaknya tersebuT

mendapatkan hasil bahwa tax amnesty berpengaruh positif terhadap tingkat kepatuhan wajib pajak.

H3 : Kebijakan tax amnesty berpengaruh positif terhadap kepatuhan wajib pajak orang pribadi pada KPP Pratama Sukoharjo.

4. Pengaruh sanksi perpajakan terhadap kepatuhan wajib pajak orang pribadi

Menurut Faisal (2009: 37) menyatakan bahwa walaupun ada potensi penerimaan negara pada setiap sanksi, namun motivasi penerapan sanksi adalah agar wajib pajak patuh melaksanakan kewajiban perpajakannya.

H4 : Sanksi perpajakan berpengaruh positif terhadap kepatuhan wajib pajak orang pribadi pada KPP Pratama Sukoharjo

5. Pengaruh sistem administrasi perpajakan modern terhadap kepatuhan wajib pajak orang pribadi Terdapat pengaruh positif dan signifikan secara parsial sistem administrasi perpajakan modern pada kepatuhan Wajib Pajak Orang Pribadi di Fakultas Ekonomi dan Bisnis Universitas Brawijaya Malang.

H5 : Sistem administrasi perpajakan modern berpengaruh positif terhadap kepatuhan wajib pajak orang pribadi pada KPP Pratama Sukoharjo

\section{METODE PENELITIAN}

Jenis penelitian yang dilakukan yaitu penelitian kualitatif. Penelitian kualitatif adalah penelitian yang digunakan untuk menyelidiki, menemukan dan menjelaskan kualitas atau keistimewaan dari pengaruh sosial yang tidak dapat dijelaskan melalui pendekatan kuantitatif. Objek dari penelitian ini adalah kepatuhan wajib pajak orang pribadi pada KPP Pratama Sukoharjo. Variabel yang digunakan dalam penelitian ini, yaitu variabel terikat (Y) kepatuhan wajib pajak orang pribadi $\left(\mathrm{X}_{1}\right)$ kualitas layanan $\left(\mathrm{X}_{2}\right)$ religiuitas pembayaran pajak, (X3) kebijakan tax amnesty, $\left(\mathrm{X}_{4}\right)$ sanksi perpajakan, $\left(\mathrm{X}_{5}\right)$ sistem administrasi perpajakan modern. Sumber data yang digunakan sumber data primer. Populasi dalam penelitian ini yaitu wajib pajak orang pribadi yang terdapat di KPP Pratama Sukoharjo. Jumlah sampel yang digunakan dalam penelitan ini 100 orang wajib pajak yang terdaftar di KPP Pratama Sukoharjo. Metode penentuan sampel yang digunakan dalam penelitian ini adalah dengan menggunakan metode 
accidental sampling, yaitu teknik penentuan sampel berdasarkan kebetulan, yaitu siapa saja yang secara kebetulan bertemu dengan peneliti dapat digunakan sebagai sampel, apabila orang yang kebetulan ditemui dipandang cocok sebagai sumber data dan memenuhi kriteria sebagai responden. Rumus Slovin digunakan untuk mengukur jumlah serta ukuran sampel.

\section{HASIL DAN PEMBAHASAN}

\section{Deskripsi Umum Responden}

Tabel 1

Karakteristik Responden Penelitian

\begin{tabular}{ccc}
\hline Kriteria & Keterangan & Jumlah \\
\hline Jenis Kelamin & Laki-laki & 57 \\
& Perempuan & 43 \\
& Total & 100 \\
\hline Pendidikan & SMA/SMK & 20 \\
Terakhir & Diploma & 27 \\
& S1 & 43 \\
& S2 & 10 \\
& S3 & - \\
& Total & 100 \\
\hline Usia & $<30$ tahun & 44 \\
& $>30$ tahun & 56 \\
& Total & 100 \\
\hline
\end{tabular}

2. Analisis Statistik Deskriptif

a. Uji Statistik Deskriptif

Tabel 2

Hasil Uji Descriptive Statistics

\begin{tabular}{cccc}
\hline & Mean & $\begin{array}{c}\text { Std. } \\
\text { Deviation }\end{array}$ & $\mathrm{N}$ \\
\hline $\mathrm{Y}$ & 30.95 & 3.092 & 100 \\
\hline $\mathrm{X} 1$ & 22.02 & 2.305 & 100 \\
\hline $\mathrm{X} 2$ & 12.85 & 1.641 & 100 \\
\hline $\mathrm{X} 3$ & 21.36 & 2.204 & 100 \\
\hline $\mathrm{X} 4$ & 21.74 & 2.334 & 100 \\
\hline $\mathrm{X} 5$ & 21.58 & 2.535 & 100 \\
\hline
\end{tabular}

3. Uji Instrumen Penelitian

a. Uji Validitas

Tabel 3

Uji Validitas

\begin{tabular}{cccc}
\hline No Item Peryataan & Sig & Standar & Keterangan \\
\hline Variabel : Kualitas Layanan (X1) & & \\
\hline 1 & .000 & $<0.05$ & Valid \\
2 & .000 & $<0.05$ & Valid \\
3 & .000 & $<0.05$ & Valid \\
4 & .000 & $<0.05$ & Valid \\
5 & .000 & $<0.05$ & Valid \\
\hline Variabel : Religiuitas Pembayaran Pajak (X2) & & \\
1 & .000 & $<0.05$ & Valid \\
2 & .000 & $<0.05$ & Valid \\
3 & .000 & $<0.05$ & Valid \\
Variabel : Kebijakan Tax Amnesty (X3) & & \\
1 & .000 & $<0.05$ & Valid \\
2 & .000 & $<0.05$ & Valid \\
3 & .000 & $<0.05$ & Valid \\
4 & .000 & $<0.05$ & Valid \\
5 & .000 & $<0.05$ & Valid \\
1 & & & \\
2 & .000 & $<0.05$ & Valid \\
3 & .000 & $<0.05$ & Valid \\
4 & .000 & $<0.05$ & Valid \\
5 & .000 & $<0.05$ & Valid \\
Variabel : Sanksi Perpajakan (X4) & $<0.05$ & Valid \\
2 & .000 & $<0.05$ & \\
3 & .000 & $<0.05$ & Valid \\
5 & .000 & $<0.05$ & Valid \\
5 & .000 & $<0.05$ & Valid \\
& .000 & & Valid \\
Variabel : Sistem Administrasi Perpajakn Modern & & Valid \\
\hline & .000 &
\end{tabular}


Dalam uji variabel menentukan apakah valid atau tidak maka dilihat pada nilai signifikasnsi, jika signifikansi $<0.05$ maka item valid, dan sebaliknya apabila signifikansi $>0.05$ maka item tidak valid.
Dari Tabel 2 diatas terlihat bahwa signifikansi $<$ dari 0.05 maka item pertanyaan yang digunakan dalam kuesioner valid.

\section{b. Uji Reliabilitas}

Tabel 4

Uji Reliabilitas

\begin{tabular}{|l|c|c|c|}
\hline \multicolumn{1}{|c|}{ Uji Reliabilitas } & $\begin{array}{c}\text { Cronbach's } \\
\text { Alpha }\end{array}$ & Sig & Keterangan \\
\hline Kualias Layanan (X1) & .783 & $>0.6$ & Reliabel \\
\hline $\begin{array}{l}\text { Religiuitas Pembayaran } \\
\text { Pajak (X2) }\end{array}$ & .826 & $>0.6$ & Reliabel \\
\hline $\begin{array}{l}\text { Kebijakan Tax Amesty } \\
\text { (X3) }\end{array}$ & .794 & $>0.6$ & Reliabel \\
\hline $\begin{array}{l}\text { Sanksi Perpajakan (X4) } \\
\text { Sistem Administrasi }\end{array}$ & .806 & $>0.6$ & Reliabel \\
$\begin{array}{l}\text { Perpajakan Modern } \\
\text { (X5) }\end{array}$ & .834 & $>0.6$ & Reliabel \\
\hline $\begin{array}{l}\text { Kepatuhan Wajib Pajak } \\
\text { (Y) }\end{array}$ & .843 & $>0.6$ & Reliabel \\
\hline
\end{tabular}

Hasil pengujian reliabilitas terhadap semua variabel dengan Cronbach's Alpha sebagaimana terlihat pada tabel 3 menunjukkan bahwa nilai Cronbach's
Alpha lebih dari 0.6 oleh karena itu dapat ditentukan bahwa semua variabel dalam instrumen penelitian ini adalah reliabel.

\section{Uji Asumsi Klasik}

\section{a. Uji Normalitas}

b.

Tabel 4

Uji Normalitas

\begin{tabular}{ccccc}
\hline Variabel & N & $\begin{array}{c}\text { Asymp. } \\
\text { Sig (2- } \\
\text { tailed) }\end{array}$ & Standar & Keterangan \\
\hline $\begin{array}{c}\text { Unstandardized } \\
\text { Residual }\end{array}$ & 100 & .083 & $>0.05$ & $\begin{array}{c}\text { Terdistribusi } \\
\text { Normal }\end{array}$ \\
\hline
\end{tabular}

Pengujian yang dilakukan menggunakan Kolmogorov-Smirnov yaitu Subyek dengan taraf signifikan $(\alpha) 0.05$ apabila $\mathrm{X}$ $>0.05$ maka data terdistribusi dengan normal atau sebaliknya. Berdasarkan tabel diatas, nilai Asymp. Sig (2-tailed) adalah 0.083 $>0.05$ maka data terdistribusi dengan normal.

\section{c. Uji Multikolinearitas}

Tabel 5

Uji Multikolinearitas

\begin{tabular}{lccccc}
\hline Variabel Independen & Toleranc & Std. & VIF & Std. VIF & Keterangan \\
& $e$ & Tolerance & & & \\
\hline Kualias Layanan & 0.973 & $>0.10$ & 1.028 & $<10$ & Tidak Terjadi Multikolinearitas
\end{tabular}




\begin{tabular}{lccccc} 
Religiuitas Pembayaran Pajak & 0.964 & $>0.10$ & 1.037 & $<10$ & Tidak Terjadi Multikolinearitas \\
$\begin{array}{l}\text { Kebijakan Tax Amesty } \\
\text { Sanksi Perpajakan }\end{array}$ & 0.752 & $>0.10$ & 1.330 & $<10$ & Tidak Terjadi Multikolinearitas \\
$\begin{array}{l}\text { Sistem Administrasi Perpajakan } \\
\text { Modern }\end{array}$ & 0.752 & $>0.10$ & 1.330 & $<10$ & Tidak Terjadi Multikolinearitas \\
\hline
\end{tabular}

Dari Tabel 5 dapat diketahui tidak terjadi multikolinearitas dari penelitian ini. Hal ini ditunjukkan dengan nilai Tolerance Value lebih besar dari 0.1 dan nilai VIF lebih kecil dari 10 .

\section{d. Uji Autokorelasi}

Tabel 6

Hasil Uji Autokorelasi

\begin{tabular}{|l|l|l|l|lr|}
\hline Durbin-Watson & $\mathrm{dU}$ & 4-dU & Standar & Keterangan & \\
\hline 1.932 & 1.7804 & 2.2196 & $\mathrm{Du}<\mathrm{DW}<4-\mathrm{dU}$ & $\begin{array}{l}\text { Tidak terjadi } \\
\text { autokorelasi }\end{array}$ & \\
\hline
\end{tabular}

Dari tabel diatas terlihat bahwa nilai DW terletak antara dU dan 4-Du (1.784
$<1.932<2.2196$ ) sehingga hasilnya tidak ada autokorelasi pada model regre

\section{e. Uji Heterokedastisitas}

Tabel 7

Uji Heterokedastisitas

\begin{tabular}{|c|c|c|c|}
\hline Variabel & $\begin{array}{c}\text { Sig } \\
(2- \\
\text { tailed) }\end{array}$ & $\begin{array}{c}\text { Std. } \\
\text { Sig }\end{array}$ & Keterangan \\
\hline Kualias Layanan & 0.981 & $>0,05$ & Bebas heterokedastisitas \\
\hline $\begin{array}{l}\text { Religiuitas } \\
\text { Pembayaran Pajak }\end{array}$ & 0.483 & $>0,05$ & Bebas heterokedastisitas \\
\hline $\begin{array}{l}\text { Kebijakan Tax } \\
\text { Amesty }\end{array}$ & 0.787 & $>0,05$ & Bebas heterokedastisitas \\
\hline Sanksi Perpajakan & 0.971 & $>0,05$ & Bebas heterokedastisitas \\
\hline $\begin{array}{l}\text { Sistem Administrasi } \\
\text { Perpajakan Modern }\end{array}$ & 0.885 & $>0,05$ & Bebas heterokedastisitas \\
\hline
\end{tabular}

Tes Heteroskdastisitas penelitian ini memakai metode Spearmans' rho yaitu mengorelasikan variabel independen dengan residualnya. Berdasarkan tabel di atas, hasil menunjukkan bahwa signifikasi $>0.05$ maka dapat dikatakan tidak ada masalah heteroskedatisitas.

\section{Uji Kelayakan Model}

a. Model Regresi

Tabel 7

Tabel Model Regresi

\begin{tabular}{llcc}
\hline & Model & B \\
\hline 1 & (Constant) & & 18.019 \\
& Kualias Layanan & -0.078
\end{tabular}


$\begin{array}{ll}\text { Religiuitas Pembayaran Pajak } & 0.057\end{array}$

Kebijakan Tax Amesty $\quad 0.098$

$\begin{array}{ll}\text { Sanksi Perpajakan } & 0.375\end{array}$

$\begin{array}{ll}\text { Sistem Administrasi Perpajakan Modern } & 0.169\end{array}$

\section{b. Uji F}

Tabel 8

Uji F

\begin{tabular}{cccccc}
\hline Model & F hitung & F tabel & Sig & Standar & Keterangan \\
\hline Regresi 1 & 3.726 & 2.469 & 0.004 & $<0.05$ & Model Layak \\
\hline
\end{tabular}

$\mathrm{F}$ hitung $>\mathrm{F}$ Tabel $(3.726>2.469)$ dan Signifikansi $<0.05(0.004<0.05)$, maka H0 ditolak. Jadi dapat disimpulkan bahwa kualitas layanan, religiuitas pembayaran pajak, kebijakan tax amesty, sanksi perpajakan, sistem administrasi perpajakan modern secara simultan mempengaruhi kepatuhan wajib pajak.

\section{c. Uji Hipotesis}

Tabel 9

Uji Hipotesis (Uji-t)

\begin{tabular}{cccccc}
\hline Hipotesa & t hitung & $\mathrm{t}$ tabel & Sig & Standar & Keterangan \\
\hline H1 & -0.545 & 1.986 & 0.545 & 0.05 & Ditolak \\
H2 & 0.318 & 1.986 & 0.751 & 0.05 & Ditolak \\
H3 & 0.645 & 1.986 & 0.521 & 0.05 & Ditolak \\
H4 & 2.606 & 1.986 & 0.011 & 0.05 & Diterima \\
H5 & 2.006 & 1.986 & 0.021 & 0.05 & Diterima \\
\hline
\end{tabular}

Uji hipotesis dari penelitian ini menggunakan uji t. Berdasarkan tabel diatas,

jika nilai t hitung $>$ t tabel dan sig $<0.05$ berarti variabel secara parsial mempengaruhi variabel dependen.

\section{d. Uji Koefisien Determinasi $\left(\mathbf{R}^{2}\right)$}

Tabel 1.

Hasil Uji Koefisien Determinasi $\left(\mathbf{R}^{\mathbf{2}}\right)$

\begin{tabular}{cccc}
\hline $\mathrm{R}$ & $\mathrm{R}$ Square & Adjusted R Square & Keterangan \\
\hline 0.407 & 0.165 & 0.121 & Berpengaruh sebesar \\
& & & $12,1 \%$ \\
\hline
\end{tabular}

Berdasarkan tabel diatas, nilai $\mathrm{R}^{2}$ sebesar 0,121 . Hal ini berarti presentase sumbangan pengaruh variabel independen terhadap variabel dependen sebesar $12 \%$ sedangkan sisanya sebesar $88 \%$ dipengaruhi oleh variabel lain diluar variabel yang diteliti.

\section{PEMBAHASAN}

Kualitas layanan adalah penyebab eksternal karena berasal dari luar Wajib Pajak atau hasil dari pemaksaan situasi. Persepsi Wajib Pajak mengenai kualitas layanan dari otoritas pajak akan mempengaruhi penilaian setiap Wajib Pajak untuk berperilaku sesuai dengan kewajiban perpajakan. Jumlah banyak wajib pajak yang menyebabkan antrean panjang layanan pajak yang membuat wajib pajak tidak nyaman. Pada hari biasa, antrean layanan tidak terjadi, sehingga wajib pajak mendapatkan layanan maksimal. Selain itu, upaya untuk meningkatkan kualitas layanan melalui fasilitas pendukung seperti komputer dan layanan berbasis online juga masih belum digunakan secara efektif dan efisien. Religiuitas pembayaran pajak tidak berpengaruh terhadap kepatuhan wajib pajak. 
Religiusitas mengacu pada keterikatan individu dengan nilai-nilai agama yang dianut. Variabel religiusitas memiliki peran dalam perilaku pembayar pajak dalam memenuhi kewajiban pajaknya. Konsekuensi religiusitas berkaitan dengan seseorang yang bersedia untuk berkomitmen pada ajaran agama dan menerapkan ajarannya dalam kehidupan sehari-hari. Ketika perilaku individu mencerminkan komitmen dalam agamanya, diharapkan untuk menjadi kontrol perilaku yang tepat dalam semua aspek yang baik dalam hal kepatuhan dalam perpajakan.

Kebijakan Tax Amnesty tidak berpengaruh signifikan terhadap kepatuhan wajib pajak. Hal ini mendukung penelitian yang dilakukan Kebijakan tax amnesty berpengaruh negatif terhadap kepatuhan wajib pajak. Penghindaran pajak yang dilakukan oleh pengusaha atau badan akan berdampak pada beban pajak yang harus dibayar oleh wajib pajak. Wajib pajak yang jujur membayarkan pajak akan menjadi lebih berat. Hal ini adanya ketidakadilan yang tinggi.

Sanksi perpajakan berpengaruh terhadap kepatuhan wajib pajak. Hasil penelitian ini menunjukkan bahwa sanksi perpajakan ditujukan kepada Wajib Pajak yang tidak patuh dalam memenuhi kewajiban perpajakannya dan disesuaikan dengan tingkat pelanggaran yang dilakukan. Diterapkannya sanksi perpajakan yang tegas dan sesuai dengan pelanggaran yang dilakukan diharapkan dapat menimbulkan efek jera sehingga Wajib Pajak dapat disiplin dalam memenuhi kewajiban perpajakannya dan dapat meningkatkan kepatuhan Wajib Pajak.

\section{KESIMPULAN DAN SARAN}

Hasil analisis data dan pembahasan di atas maka dapat disimpulkan bahwa secara parsial Kualitas Layanan, Religiuitas pembayaran pajak, Kebijakan Tax Amnesty tidak berpengaruh terhadap kepatuhan wajib pajak pada KPP Pratama Sukoharjo. Sanksi perpajakan, sistem administrasi perpajakan modern berpengaruh positif terhadap kepatuhan wajib pajak pada KPP Pratama Sukoharjo. Namun, secara simultan Kualitas layanan, Religiuitas Pembayaran Pajak, Kebijakan Tax Amnesty, Sanksi Pajak dan Sistem Administrasi Perpajakan Modern berpengaruh secara simultan terhadap Kepatuhan Wajib Pajak Orang Pribadi Pada KPP Pratama Sukoharjo.

Keterbatasan dalam penelitian ini adalah (1) penelitian ini hanya meneliti satu objek saja yaitu KPP Pratama Sukoharjon sehingga tidak dapat digeneralisasikan. (2) variabel yang digunakan terbatas. Berdasarkan hasil analisis data dan simpulan yang telah dilakukan, dapat diajukan beberapa saran untuk penelitian selanjutnya. Penelitian selanjutnya diharapkan dapat menguji pengaruh terhadap kepatuhan wajib pajak dengan variabel lainnya seperti kesadaran pajak atau yang lainnya diluar variabel ini sehingga dapat memperoleh hasil yang variatif.

\section{DAFTAR PUSTAKA}

\author{
Chau, L. (2009). A Critical Review of \\ Fisher Tax Compliance Model (A \\ Research Syntesis). Journal of \\ Acconting and Taxation, Vol 1 No 2, \\ 34-40.
}

\author{
Mardiasmo. (2013). Perpajakan Edisi \\ Revisi. Penerbit Andi.
}

